\title{
Cystic Echinococcosis/Hydatid Cyst Coinfection with HIV: A Report from Shiraz, Iran
}

\author{
Yosef Sharifi $\mathbb{D}^{1},{ }^{1}$ Seyed Mahmoud Sadjjadi $\mathbb{D}^{1,2}$ Hamed Nikoupour Dailami ${ }^{1}{ }^{3}$ \\ Seyed Hamed Jafari $\left(\mathbb{D},{ }^{4}\right.$ Mohammad Hossein Anbardar $\left(\mathbb{D},{ }^{5}\right.$ \\ and Mohammad Bagher Khosravi $\mathbb{D}^{6}$
}

${ }^{1}$ Department of Parasitology and Mycology, School of Medicine Shiraz University of Medical Sciences, Shiraz, Iran

${ }^{2}$ Basic Sciences in Infectious Diseases Research Center, Shiraz University of Medical Sciences, Shiraz, Iran

${ }^{3}$ Department of Transplantation, Shiraz University of Medical Sciences, Shiraz, Iran

${ }^{4}$ Medical Imaging Research Center, Shiraz University of Medical Sciences, Shiraz, Iran

${ }^{5}$ Department of Pathology, Shiraz Transplant Center, Abu Ali Sina Hospital, Shiraz University of Medical Sciences, Shiraz, Iran

${ }^{6}$ Department of Anesthesia, Shiraz Anesthesia and Critical Care Research Center, Shiraz, Iran

Correspondence should be addressed to Seyed Mahmoud Sadjjadi; smsadjjadi@sums.ac.ir

Received 8 August 2020; Revised 2 January 2021; Accepted 18 January 2021; Published 23 February 2021

Academic Editor: Yu-Chen Fan

Copyright (C) 2021 Yosef Sharifi et al. This is an open access article distributed under the Creative Commons Attribution License, which permits unrestricted use, distribution, and reproduction in any medium, provided the original work is properly cited.

\begin{abstract}
HIV coinfected with other parasitic diseases may cause a serious problem for the patients. A few case reports describing echinococcosis with human immunodeficiency virus (HIV) infection have been reported in the world; however, it has not been reported in Iran, so far. Here, the first case of liver hydatid cyst coinfected with HIV in Iran is reported. The patient is a 46-year-old female HIV-positive based on the laboratory report. Her clinical symptoms included abdominal pain, abdominal enlargement, and anorexia. Ultrasound showed three large hepatic hydatid cysts with hundreds of daughter cysts. Ultrasonography of the cyst revealed it as a CE2 stage according to the WHO classification. The patient went under complete anesthesia followed by complete cyst removal by surgery. Observation of the hydatid cyst fluid using eosin $0.1 \%$ revealed more than $70 \%$ viable protoscoleces. Histopathology examination, polymerase chain reaction (PCR), and viable protoscoleces confirmed the diagnosis of echinococcosis. The IgG ELISA test with native AgB for E. granulosus infection was also positive. mtDNA amplification using PCR and sequencing showed the cyst as E. granulosus sensu stricto genotype. Our observations show that huge, large, and high-pressure cysts with hundreds of daughter cysts are difficult to be completely removed, and drug treatment has not been able to reduce their size. Therefore, in HIV coinfection with hydatid cyst, surgery is preferable to other treatments.
\end{abstract}

\section{Introduction}

Cystic echinococcosis (CE) is an important zoonotic parasite infection that is caused by the larval form of Echinococcus granulosus sensu lato (s.l.) [1]. E. granulosus s.l. consists of E. granulosus sensu stricto (s.s.) (genotypes G1-G3), E. equinus (genotype G4), E. ortleppi (genotype G5), E. canadensis cluster (genotypes G6-8 and G10), and E. felidis [2]. Human is a random intermediate host for the parasite whom the larval stage or metacestode can be located in different organs of this host [3]. The prevalence of CE in different organs reaches $70 \%$ in the liver, $20 \%$ in the lung, and $10 \%$ in other organs (brain, muscle, pericardium, kidney, eyes, and bone marrow) [4]. Diagnosis of hydatid cyst is based on clinical symptoms, imaging (ultrasonography, CT scan and MRI), and serologic methods, especially based on the use of native antigens B [5]. Ultrasonography is usually the first diagnostic line which is classified by WHO as CE1 to CE5 [6].

The disease has been reported in humans from all parts of Iran so that a total of $1 \%$ of patients admitted to the surgery departments harbored this disease [7]. Although parasitic infections are unusual by cestodes in HIV-infected patients [8], hydatid cyst has been reported in HIV patients 


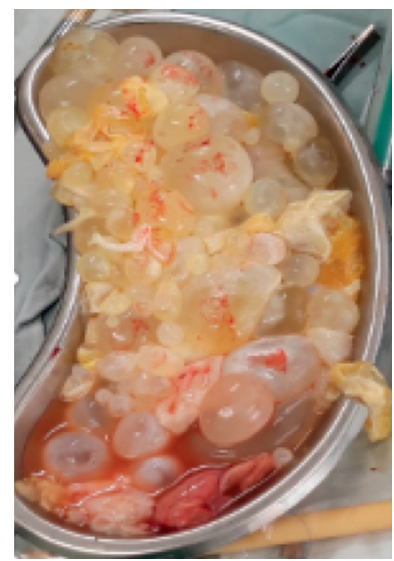

(a)

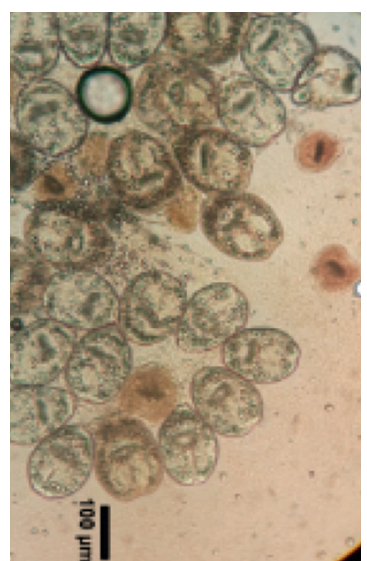

(b)

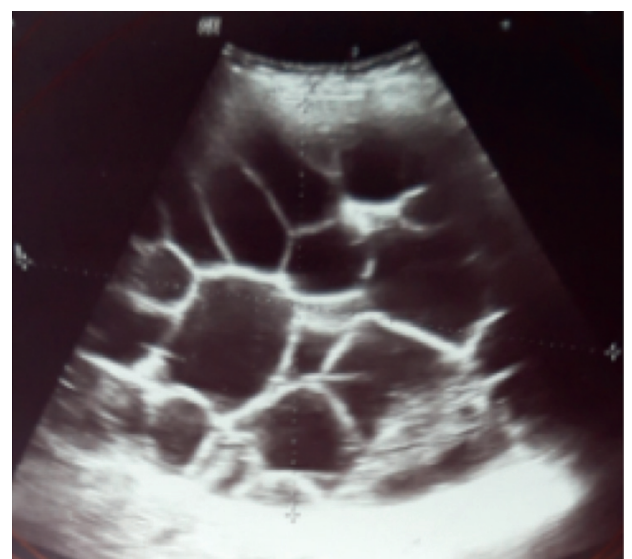

(c)

Figure 1: (a) Hundreds of daughter cysts removed from CE patient. (b) Using eosin $0.1 \%$ on the protoscoleces collected from cysts revealed more than $70 \%$ viability (viable protoscoleces do not stain by eosin). (c) Abdominal ultrasound showing a large multiloculated cyst on the liver which was classified as CE2 stage according to the WHO classification.

in Australia, Turkey, India, Spain, Romania, Netherlands, Switzerland, and Brazil [9-19]. However, the hydatid cyst has not been reported in HIV patients in Iran, so far. This study aimed to report rare cases of hydatid cyst coinfected with HIV in Iran so that the cysts were significantly enlarged, and this may be due to a defective immune system. Surgery is very important in the recovery and survival of the patient.

\section{Case Presentation}

A 46-year-old female with HIV infection was admitted to Abu Ali Sina hospital, with some clinical symptoms including abdominal pain, abdominal enlargement, and anorexia. Symptoms of hydatid cyst started with abdominal pain about a year before surgery, and over time, as the abdomen enlarged, anorexia appeared. She is a housewife, living in the village (around Shiraz, Iran), and in contact with domestic animals (sheep, cows, goats, etc.) and dogs. She contracted HIV around 2014 from having sex with her husband and was treated for HIV immediately after diagnosis, and the HIV viral load (copies/ml) was not detected before surgery. Based on her clinical signs, abdominal ultrasound was done which showed three large multiloculated cysts on her liver with a size of $100 \times 80 \mathrm{~mm}$ in the right lobe, $74 \times 55 \mathrm{~mm}$ in the subdiaphragmatic aspect, and $200 \times 130 \mathrm{~mm}$ adjacent to the lower border of the left lobe. The stage of all cysts was CE2 according to the WHO classification (Figure 1(c)). The IgG ELISA test using native $\mathrm{AgB}$ on the sera of the patient revealed a positive result for $\mathrm{CE}$. The patient went under complete anesthesia, followed by partial cystectomy with the following procedure: incision and drainage of the cysts, closure of biliary fistulas, T-tube insertion in the common bile duct, and two mushroom drain insertion in cyst cavities. Hypertonic saline was used as a scolicidal agent during surgery. All three cysts possess hundreds of daughter cysts (Figure 1(a)). The patient was treated with albendazole ( $400 \mathrm{mg}$ twice daily) for 4 weeks before surgery and the same dose for 3 months after surgery.
The cysts were fertile so that using eosin $0.1 \%$ on the protoscoleces collected from cysts revealed more than $70 \%$ viability (Figure 1(b)). Histopathology of the specimens (Figure 2) showed the destruction of liver parenchyma by hydatid cyst and replacement by fibrosis and foreign bodytype giant cell reaction (Figure 2(d)), and sections of a laminated membrane, a protoscolex, and a hooklet of $\mathrm{CE}$ (Figures 2(a)-2(c), respectively).

The laboratory data are in Table 1 which shows red blood cells (RBCs), hemoglobin ( $\mathrm{Hb})$, hematocrit (HCT) were less than normal pre- and postsurgery. Although MCV and $\mathrm{MCH}$ and alkaline phosphatase (ALP) were higher than normal. DNA was extracted from protoscoleces for PCR. Application of specific primers JB3 and JB4.5 for the cox1 gene [20] followed by sequencing showed the cyst as E. granulosus sensu stricto genotype (accession number: MT073987). The patient has a normal life 18 months after surgery.

\section{Discussion}

Cystic echinococcosis is widespread in many parts of the world including Mediterranean countries where many dogs and their environments are infected. So, the people living in these areas are at risk of infection. Humans are usually infected by ingesting the eggs of the parasite from the environment and dogs [21]. Hydatidosis is a silent disease, especially in the case of liver involvement. Therefore, the cysts may survive for a prolonged period and sometimes do not display outstanding symptoms. Clinical symptoms may develop when the cysts become large enough to press other organs and causing pain or cause visual abdominal swelling. Frequently, patients complain of abdominal pain in the right upper quadrant [22]. Abdominal pain has been the main symptom sometimes together with hepatomegaly, epigastric tenderness, jaundice, and abdominal enlargement $[9,10,12,13]$. Our case had abdominal pain, abdominal enlargement which was common to other reported 

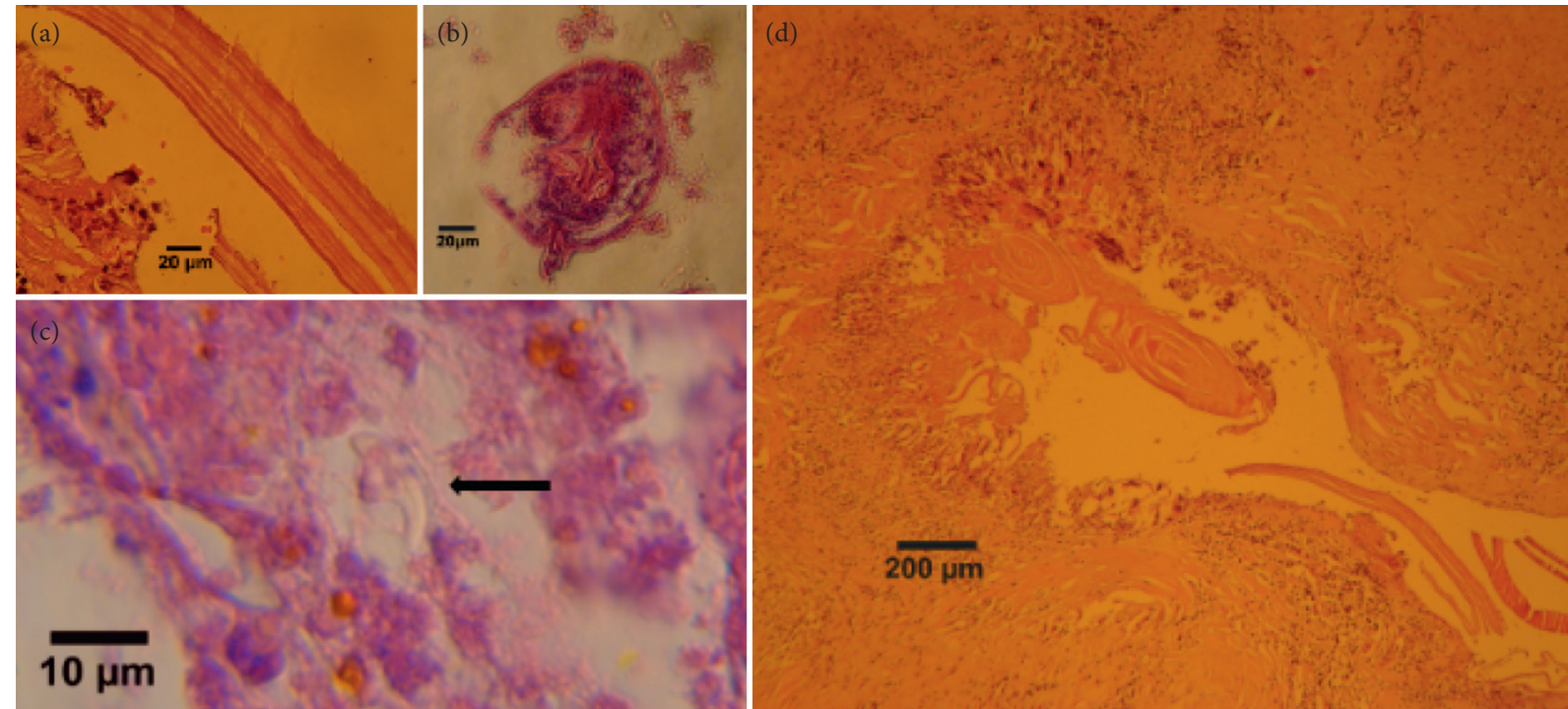

Figure 2: Section of hydatid cyst stained with H\&E. (a) Laminated membrane. (b) Protoscolex (with hook and calcareous body). (c) Hooklet. (d) Destruction of liver parenchyma by the hydatid cyst and replacement by fibrosis and giant cell.

TABLE 1: Comparison of the laboratory data including blood and sera tests, during pre- and postsurgery times shows the differences.

\begin{tabular}{|c|c|c|c|c|}
\hline \multirow{2}{*}{ Laboratory test } & \multicolumn{2}{|c|}{ Presurgery } & \multirow{2}{*}{$\begin{array}{c}\text { Surgery } \\
\text { May 20, } 2019\end{array}$} & \multirow{2}{*}{$\begin{array}{c}\text { Postsurgery } \\
\text { May 24, } 2019\end{array}$} \\
\hline & April 14, 2019 & April 25, 2019 & & \\
\hline WBC $\left(10^{6} / \mathrm{L}\right)$ & 7.2 & 10.5 & & $\mathbf{L}^{*} 4.3$ \\
\hline EOS $(\%)$ & 2 & 1 & & $\mathbf{H}^{*} 14$ \\
\hline $\operatorname{RBC}\left(10^{6} / \mu \mathrm{L}\right)$ & 2.39 & 2.15 & & 2.3 \\
\hline $\mathrm{Hb}(\mathrm{g} / \mathrm{dL})$ & L 9.3 & L 8.3 & & L 8.2 \\
\hline $\operatorname{HCT}(\%)$ & L 27.1 & L 24.7 & & L 24 \\
\hline $\mathrm{MCV}(\mathrm{fL})$ & H 113.4 & H 114.88 & & H 104.35 \\
\hline $\mathrm{MCH}(\mathrm{pg})$ & H 38.91 & H 38.6 & & H 35.65 \\
\hline $\mathrm{MCHC}(\mathrm{g} / \mathrm{dL})$ & 34.32 & 33.6 & & 34.17 \\
\hline Plt $\left(10^{6} / \mathrm{L}\right)$ & 281 & 414 & & 297 \\
\hline BUN (mg/dL) & 10 & 12 & & L 5 \\
\hline $\mathrm{Cr}(\mathrm{mg} / \mathrm{dL})$ & 0.85 & 1.0 & & 0.7 \\
\hline AST (U/L) & 22 & 18 & & 15 \\
\hline $\operatorname{ALT}(\mathrm{U} / \mathrm{L})$ & 17 & 8 & & 10 \\
\hline $\operatorname{ALP}(\mathrm{U} / \mathrm{L})$ & 230 & H 352 & & H 314 \\
\hline Total bilirubin (mg/dL) & 0.58 & 0.69 & & 0.43 \\
\hline Direct bilirubin $(\mathrm{mg} / \mathrm{dL})$ & 0.27 & 0.29 & & 0.23 \\
\hline Albumin $(\mathrm{g} / \mathrm{dL})$ & 4.4 & 3.7 & & L 2.9 \\
\hline Total protein $(\mathrm{g} / \mathrm{dL})$ & & 8.8 & & 6.6 \\
\hline CD4 T-cell count $(420-1250$ cells $/ \mathrm{ml})$ & L 377 & & & L 333 \\
\hline
\end{tabular}

${ }^{*} \mathrm{~L}$ : light; H: high.

symptoms, and also anorexia which was not reported in other cases $[9,10,12,13]$. Table 2 compares cases of coinfection with CE and HIV.

HIV coinfection with cestode diseases has been reported, including CE, alveolar echinococcosis (AE), polycystic echinococcosis, and neurocysticercosis [9-19], but HIV coinfection with $\mathrm{CE}$ is more common which could be due to the higher prevalence of E. granulosus in the world [9-19]. Such coinfected disease has been reported in hepatic CE, spinal $\mathrm{CE}$, pulmonary $\mathrm{CE}$, renal $\mathrm{CE}$, and hepatorenal $\mathrm{CE}$ [9-19]. All previous liver cases were male, but our case was female. Although patients have been in the middle age (between 28 and 47 years), a 5-year-old boy with hepatorenal hydatidosis and AIDS also has been reported [9, 10, 12, 13].

Based on the WHO categorization of the stages of human liver CE [6], the isolated cyst was categorized as CE2 which is similar to three out of four patients identified in the work of Ran et al. [9]. Miron et al. showed presurgery chemotherapy of echinococcal infections can reduce the size and number of viable protoscoleces [23]. However, in our case, although she was treated with albendazole $(400 \mathrm{mg}$ twice daily) for 4 weeks before surgery, no change was observed in the size and number of live protoscoleces. In our case, the viability of protoscoleces was over $70 \%$. 


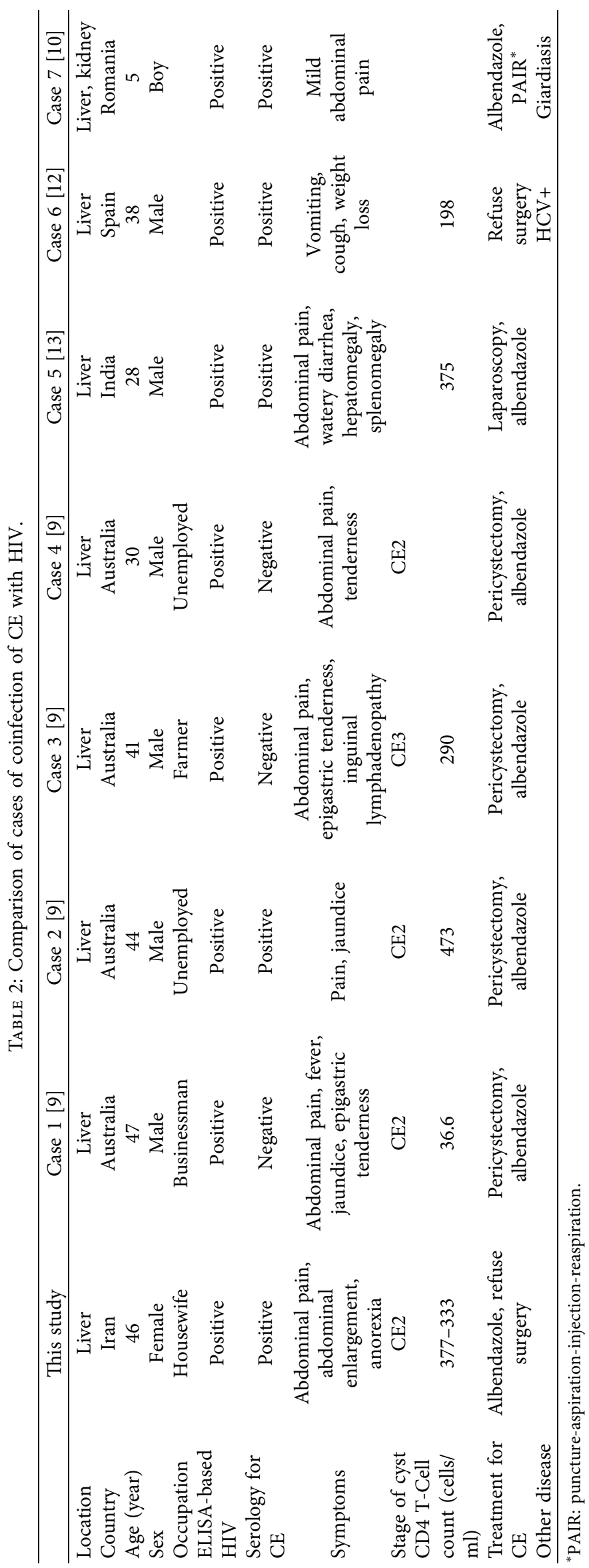


Unfortunately, this has not been reported in other cases coinfected with CE $[9,10,12,13]$.

Both humoral and cellular immunity mechanisms play essential roles in response to human hydatidosis. Th1 and Th2 cell activation and the expression of immunoglobulin isotypes such as IgG and IgE occur at different stages of the infection [24, 25]. Current evidence about the level of IgG4 and $\operatorname{IgE}$ antibodies and frequent eosinophilia in hydatid disease suggests that the dominant immune response to Echinococcus infection is the response of the TH2 (T-helper) type [26]. In this case, eosinophilia was normal before surgery $(1-2 \%)$ but increased significantly a few days after surgery (eosinophilia: 14\%). This item has not been reported in other cases coinfected with CE $[9,10,12,13]$. Hailong et al. have reported eosinophilia is not usually observed in patients with hydatid disease. In most cases, it is either mild $(<15 \%)$ or absent; although in patients with ruptured cysts in the biliary tree, eosinophilia is often marked and shows transient elevation (up to 60\%). In this study, eosinophil count was normal before the surgery, but it increased prominently after the surgery. A reason for this could be that some rupture occurred during surgical removal of the hydatid cysts [27]. Also, the increase in eosinophilia may be due to drug treatment 4 weeks before surgery, which is similar to the report of Di Comite et al. who stated eosinophilia increased from $30 \%$ to $48 \%$ after treatment [28].

HIV attacks to TCD4 cells and reduces them. Zingg et al. have suggested that especially CD4+ Th cell counts have been associated with the immune response to the parasite and the severity of Echinococcus infection [19]. The CD4 level of the present case was lower than normal, but not too low which could be due to AIDS medication. There are a few reports of CE-HIV patients with negative serology [9]. It could be because of the reduced immune response in HIV patients or due to differences in species or strain of parasite, location of the cyst, number of the cysts, cyst fertility, cyst viability, and the integrity of the cyst walls $[29,30]$.

Hydatid cyst growth is slow. Moro et al. reported that the rate of natural growth from 0.4 to $1.4 \mathrm{~cm}$ over 3 years [31]. HIV infection may aggravate hydatid cyst or accelerate cyst growth, producing huge or large cyst with even hundreds of daughter cysts $[9,18]$. Chauchet et al. reported that, in patients infected with E. multilocularis and immunodeficiency, such as AIDS, the protoscoleces proliferation appear uncontrolled, leading to a very rapidly progressing disease status [32]. Finding the large cysts in the present patient could be due to HIV infection. A literature review (Table 2) showed that, from seven cases of CE-with HIV coinfection, a total of five cases have been gone under surgery or PAIR (percutaneous aspiration, injection, and reaspiration) $[9,10,13]$, but in two cases who had refused surgery, death had occurred $[9,12]$. The present case was also recovered after surgery.

\section{Conclusion}

Our observations showed while drug treatment has not been able to reduce the size of large cysts, complete removal of huge cysts with high pressure and hundreds of daughter cysts is also difficult. However, surgery is preferable to other treatments in cystic echinococcosis/hydatid cyst coinfection with HIV.

\section{Data Availability}

The data used to support the findings of this study are included within the article.

\section{Consent}

Written informed consent was obtained from the patient for publication of this case report and any accompanying images.

\section{Conflicts of Interest}

The authors declare that they have no conflicts of interest.

\section{Authors' Contributions}

Sharifi and Sadjjadi were major contributors in writing the manuscript. Sharifi, Sadjjadi, and Nikoupour analyzed the patient's case. All authors have read and approved the final manuscript. Sadjjadi takes responsibility for the integrity of the content of the paper.

\section{Acknowledgments}

The authors thank the staff of the surgery ward at the Abu Ali Sina Hospital for their cooperation, especially Ms. Nowrouzi. This work was supported by Shiraz University of Medical Sciences (grant no. 19339).

\section{References}

[1] R. C. A. Thompson, "Biology and systematics of Echinococcus," Echinococcus and Echinococcosis, Part A, vol. 95, pp. 65-109, 2017.

[2] D. A. Vuitton, D. P. McManus, M. T. Rogan et al., "International consensus on terminology to be used in the field of echinococcoses," Parasite, vol. 27, p. 41, 2020.

[3] J. Eckert, M. A. Gemmell, F.-X. Meslin, and Z. S. Pawłowski, WHO/OIE Manual on Echinococcosis in Humans and Animals: A Public Health Problem of Global Concern, World Health Organization, Geneva, Switzerland, 2002.

[4] G. Grosso, S. Gruttadauria, A. Biondi, S. Marventano, and A. Mistretta, "Worldwide epidemiology of liver hydatidosis including the Mediterranean area," World Journal of Gastroenterology, vol. 18, no. 13, pp. 1425-1437, 2012.

[5] S. M. Sadjjadi, S. Ardehali, B. Noman-Pour, V. Kumar, and A. Izadpanah, "Diagnosis of cystic echinococcosis: ultrasound imaging or countercurrent immunoelectrophoresis?" Eastern Mediterranean Health Journal, vol. 7, pp. 907-911, 2001.

[6] WHO, "International classification of ultrasound images in cystic echinococcosis for application in clinical and field epidemiological settings," Acta Tropica, vol. 85, pp. 253-261, 2003.

[7] M. B. Rokni, "Echinococcosis/hydatidosis in Iran," Iranian Journal of Parasitology, vol. 4, pp. 1-16, 2009.

[8] S. B. McCombs, M. S. Dworkin, and P.-C. T. Wan, "Helminth infections in HIV-infected persons in the United States, 1990- 
1999," Clinical Infectious Diseases, vol. 30, no. 1, pp. 241-242, 2000.

[9] B. Ran, Y. Shao, Y. Guo et al., "Surgical treatment of hepatic cystic echinococcosis in patients co-infected with HIV/AIDS," Journal of Helminthology, vol. 90, no. 1, pp. 125-128, 2015.

[10] C. L. Calma, A. M. Neghina, B. Vlaicu, I. Iacobiciu, and R. Neghina, "A pediatric case of hepatorenal hydatidosis in a patient with human immunodeficiency virus (HIV)," Infectious Diseases in Clinical Practice, vol. 20, no. 4, pp. 285-286, 2012.

[11] M. Sailer, B. Soelder, F. Allerberger, D. Zaknun, and B. Gottstein, "Alveolar echinococcosis of the liver in a sixyear-old girl with acquired immunodeficiency syndrome," The Journal of Pediatrics, vol. 130, no. 2, pp. 320-323, 1997.

[12] J. M. Feichtinger, M. Masia, S. Padilla, E. Bernal, A. Martinhidalgo, and F. Gutiérrez, "Fatal infection due to larval cysts of cestodes (neurocysticercosis and hydatid disease) in human immunodeficiency virus (HIV) infected patients in Spain: report of two cases," Scandinavian Journal of Infectious Diseases, vol. 39, no. 8, pp. 719-723, 2007.

[13] A. Javed, R. Kalayarasan, and A. K. Agarwal, "Liver hydatid with HIV infection: an association?" Journal of Gastrointestinal Surgery, vol. 16, no. 6, pp. 1275-1277, 2012.

[14] F. B. de Almeida, C. L. Correa, N. G. de Siqueira, S. C. de Carvalho NVFM dos, R. Rodrigues-Silva, and A. F. B. de Andrade, "Histopathological findings of an uncommon co-infection : Echinococcus vogeli, $\mathrm{HIV}$, hepatitis $\mathrm{C}$ virus, and hepatitis B virus," International Journal of Infectious Diseases, vol. 17, pp. 925-927, 2013.

[15] P. Bhirud, P. Bhirud, and S. Kankalia, "Isolated renal hydatid cyst with ureteric calculus in human immunodeficiency virus (HIV) infected patient," Medical Journal of Dr. D.Y. Patil University, vol. 7, no. 3, pp. 377-380, 2014.

[16] I. Erayman, E. Kalkan, F. Erdi, Ü. Kerimoglu, and H. Esen, "Primary spinal hydatid cyst in a patient with acquired immunodeficiency syndrome," European Spine Journal, vol. 20, no. S2, pp. 235-238, 2011.

[17] V. V. Shenoy, S. R. Joshi, A. P. Aklujkar, V. S. Kotwal, N. A. Nadkarni, and N. N. Ramraje, "Pulmonary hydatid cyst in HIV-1 disease," The Journal of the Association of Physicians of India, vol. 53, pp. 1070-1072, 2005.

[18] F. Keskin, F. Erdi, E. Kalkan, and Y. Karatas, "Recurrence of primary spinal cyst hydatid in a HIV (+) patient: a case report," Journal of the Neurological Sciences, vol. 30, pp. 455460, 2013.

[19] W. Zingg, E. C. Renner-Schneiter, E. C. Renner-Schneiter et al., "Alveolar echinococcosis of the liver in an adult with human immunodeficiency virus type-1 infection," Infection, vol. 32, no. 5, pp. 299-302, 2004.

[20] J. Bowles, D. Blair, and D. McManus, "Genetic variants within the genus Echinococcus identified by mitochondrial DNA sequencing," Molecular and Biochemical Parasitology, vol. 54, no. 2, pp. 165-173, 1992.

[21] C. N. L. Macpherson, Dogs, Zoonoses and Public Health, Macpherson CNL, Meslin F-X, Wandeler AI, Wallingford, UK, 2nd edition, 2012.

[22] H. Cummings, M. Rodriguez-Sosa, and A. R. Satoskar, Medical Parasitology (Section III. Hydatid Disease), IntechOpen, London, UK, 2009.

[23] D. Miron, B. Kawar, D. Lumelsky, R. Spiegel, and Y. Horovitz, "Encysted peritoneal hydatidosis in a child - the effectiveness of pre-operative therapy with a combination of praziquantel and albendazole," Annals of Tropical Medicine \& Parasitology, vol. 99, no. 6, pp. 577-582, 2005.
[24] W. Zhang, A. G. Ross, and D. P. Mcmanus, "Mechanisms of immunity in hydatid disease: implications for vaccine development," The Journal of Immunology, vol. 181, no. 10, pp. 6679-6685, 2008.

[25] D. Mezioug and C. Touil-Boukoffa, "Étude du profil cytokinique de patients atteints d'hydatidose: une possible application en matière d'immunosurveillance," Parasite, vol. 16, no. 1, pp. 57-64, 2009.

[26] A. Siracusano, R. Riganò, E. Ortona et al., "Immunomodulatory mechanisms during Echinococcus granulosus infection," Experimental Parasitology, vol. 119, no. 4, pp. 483-489, 2008.

[27] L. Hailong, J. Yufeng, L. Guisheng, Z. Shijie, and P. Xinyu, "Surgical treatment of multiple hydatid cysts in the liver of a pediatric patient," The American Journal of Tropical Medicine and Hygiene, vol. 92, pp. 595-598, 2015.

[28] G. Di Comite, G. Dognini, G. Gaiera, R. Ieri, and L. Praderio, "Acute echinococcosis: a case report," Journal of Clinical Microbiology, vol. 38, no. 12, pp. 4679-4680, 2000.

[29] M. D. Rickard and J. F. Williams, "Hydatidosis/cysticercosis: immune mechanisms and immunization against infection," Advances in Parasitology, vol. 21, pp. 229-296, 1982.

[30] A. Siracusano, A. Teggi, and E. Ortona, "Human cystic echinococcosis: old problems and new perspectives," Interdisciplinary Perspectives on Infectious Diseases, vol. 2009, pp. 1-7, 2009.

[31] P. L. Moro, R. H. Gilman, M. Verastegui, C. Bern, B. Silva, and J. J. Bonilla, "Human hydatidosis in the central andes of -Peru: evolution of the disease over 3 years," Clinical Infectious Diseases, vol. 29, no. 4, pp. 807-812, 1999.

[32] A. Chauchet, F. Grenouillet, J. Knapp et al., "Increased incidence and characteristics of alveolar echinococcosis in patients with immunosuppression-associated conditions," Clinical Infectious Diseases, vol. 59, no. 8, pp. 1095-1104, 2014. 